\title{
The Innovation Process Management Community Case Study: Community Justice Center in the Province of SuratThani
}

\author{
Pattaravis Yoowattana
}

\begin{abstract}
The research on the innovation process management community with Community Justice Center in the province of SuratThani as a case study is the study which is performed to find the model and perfect community justice guideline with the objective to study on the context, political culture, social structure, and cultural of local community under a multicultural society which has an effect on the process management community in SuratThani Province. In addition, it is to study on the management innovation on the process management community in SuratThani Province as well as to study the impact towards the result of successfulness or the failure of the development of innovation management on the process management community in SuratThani Province. The result of the conducted research is concluded as follows:

The activities implementation procedure of the community to perform mission of justice, including the crime and control prevention, conflict management, reduction and remedy to the damage caused by crime or violence as well as the empowering and receiving offenders back to the community. These will rely on the social solidarity and law as tools to support process management community formed by the brainstorming, participating, monitoring, and benefits receiving of people in the community. The people in the community can conduct by themselves, or they can cooperate with government sectors as it allows the access to the justice to prevent and solve crime problems as well as any regulation disorders in the community in order to build sustainable immunity and security, fairness, peace, and quality of life of the community.

From the study, it can be presented to the government and other communities in order to acknowledge and understand the context, political culture, social structure, and cultural of local community which affect the process management community in SuratThani Province, obtain innovative management knowledge to apply on the process management community within multicultural society, and realize factors affecting successfulness or failure of knowledge on the development of innovative management related to the process management community in this province.
\end{abstract}

Index Terms-Community justice innovation, SuratThani province, justice center, innovation process.

\section{INTRODUCTION}

It is now generally agreed that the right to access to justice shall be the fundamental human rights of human without the limitation on group of people or social status. Everyone shall

Manuscript received June 23, 2016; revised December 23, 2016. This work was supported in part by the research and development institute, Suan Sunandha Rajabhat University, Thailand.

Pattaravis Yoowattana is with the College of Innovation and Management at Suan Sunandha Rajabhat University, Bangkok, Thailand (e-mail: pattaravis.yo@ssru.ac.th). have opportunity to access to the justice, literally. After accessed, everyone shall be treated fairly in the Due Process and Substantive Justice when the court has equal judge, including regardless of social resonance.

From the practice in the past, there is still disparity of Justice of Thailand between rich people and poor people. It can be understood widely that it reflects the current state of society in which people have unequal "chance" in the justice system. The reason is because Justice of Thailand, since in the pass, focuses on the traditional justice procedure (mainstream) only. The method of operation for the traditional justice is to apply to the offender by using defensive strategy where police is the first barrier. This reflects the Justice of Thailand that it depends on two components: Legislative Process and Law Enforcement Process, particularly the criminal justice procedure. This procedure can be conducted legally through police agencies, prosecutors, courts, corrections and lawyers working in harmony as the process system called "The Court of Justice." At the same time, it affects the rights and freedoms of citizens as per the supreme law of the country. It can be indicated that it focuses on the Discriminatory "Legal State" until it severely lacks of "Rule of Law." In this case, the disparity in the justice system is one of the major causes of inequality of other sides, especially the disparity in resources and incomes.

As a result, the Ministry of Justice that has a mission to provide justice and fairness for the society has seen that the stop of unfairness in the society and community before the problems arise shall be the supreme target of the mission of the ministry, and the implementation to provide justice in the current mainstream can be absolutely applied to provide justice to people because it is the procedure occurred from the state (Ministry of Justice, n.d.: Introduction). Therefore, the implementation to provide alternative justice is provided as a Community Base to develop and provide justice as well as trying to drawn people to be "partners" to maintain justice with the state in order to share ideas, brainstorm, and solve the problems of the community as it shall lead to the strong basement in the dimension of justice for people at all levels truly (Ministry of Justice, n.d.: Introduction).

The process management community is counted as new topic for Thailand that is familiar with the justice system provided by the state solely for a long period of time. With this concept, it produces the habitude. The state feels that it is the ownership of the justice that monopolizes the justice, and it feels that it can provide the justice without having any cooperation and participation from people or community. People and community also feel that they have no duty in this topic, and it is the duty of state officers to operate everything. 
People only wait and take services from the state [1], [2]. Peace and order maintaining as well as assets are key mission that state shall operate. The key tool that state uses to achieve the objective is law, particularly criminal law issued to manage and control society and justice procedure which are the procedures used as a law enforcement. It contains various agencies such as polices, prosecutors, courts, corrections, and probations. However, the law enforcement procedure to control society will have features of the use of the state as a main on the operation. Sometimes, if it lacks of the appropriate monitoring mechanism, it could lead to the violation of the rights and freedoms of citizens and society, and it society will become Police State rather than Legal State. Moreover, this criminal paradigm focuses on bringing the offenders to the punishment, so it does not focus on the criminal victims and communities who have received the impacts from the offensive appropriately. The most important thing is that the social control by using criminal law as a tool can lead to the ignorance of the social justice. For the case of Thailand, it can be said that it is the main cause or the fundamental of unwanted behavior problems. From such reason, the key that leads the justice procedure to the target successfully in order to create peace for society is to build the balance of law enforcement and the right protection of non-involved person, so they will not get unreasonable impacts. The non-ignorance on social justice issue means that the treatment of offender as the central to the paradigm of restorative justice that pull out the victims and the community to join the participation shall change the way from focusing on control to the solution, specially solutions based on a framework of social justice, and it shall be a justice based on fact and not just in terms of winning or losing the case in formal justice system. With such reason, it is necessary to create a justice procedure that does not rely on the authority of state to control solely, but this procedure shall be a combination between the roles of justice procedure which is the organization of the state with the role of community and civil society in exactly the right proportions. Justice must be expanded to wider-oriented paradigm of Retributive Justice that have the offender has a central to the paradigm of Restorative Justice pull out the victims and the community to join the participation shall change the way from focusing on control to the solution, specially solutions based on a framework of social justice, and it shall be a justice based on fact and not just in terms of winning or losing the case in formal justice system. With such reason, it is necessary to create a justice procedure that does not rely on the authority of state to control solely, but this procedure shall be a combination between the roles of justice procedure which is the organization of the state with the role of community and civil society in exactly the right proportions.

SuratThani Province is 1 of 8 pilot provinces to establish Community Justice Center. And, 15 communities in the same province have been selected to join this pilot program in 2014 After having 19 pilot communities, SuratThani Province is considered as the Community Justice Center is successfully expanded. In 2015, there are projects to expand 19 Community Justice Centers nearby, including Community Justice Networks that pass the training from Ministry of Justice. Thus, there is an expansion of the result by applying process management community to use with youth group. It means that process management community is brought into each school in the community justice project to youth in each municipality area. It can be seen that SuratThani Province focuses on the importance of process management community for helping to prevent and solve criminal problems. Hence, this research is conducted to recognize role and potential of community justice network on prevention and solution of crime within the community, and how the community receives benefits from community justice network. Moreover, the problems and obstacles in applying process management community is also focused in this study in order to find ways to develop the potential of the community justice network to be stronger and able to handle people within the community as well as solving problems by themselves without relying on the government sectors.

\section{Methodology}

\section{A. Research Objective}

To study on the knowledge innovative management on model, administrative procedure and overall performances, including impacts obtained from the administration of Community Justice Center in SuratThani Province.

\section{B. Scope of the Study}

This research is the study on the context, political culture, social structure, and cultural of local community under a multicultural society which affect the process management community in Tha Rong Chang Sub-District, Punpin District, SuratThani Province and Tha Khoei sub-district community, Tha Chang District, SuratThani Province.

\section{Expected Benefits}

In this research, the group of researchers expected that the results of the study can be presented to the government and other communities in order to acknowledge and understand the context, political culture, social structure, and cultural of local community which affect the process management community in SuratThani Province, obtain innovative management knowledge to apply on the process management community within multicultural society, and realize factors affecting successfulness or failure of knowledge on the development of innovative management related to the process management community in this province.

\section{1) Literature review and related research}

\section{- Concept of the Community justice}

Community Justice means the prevention of crime in various types and activities of agencies in traditional criminal justice system that provides an opportunity for community to participate in the process of such type and activity with the goal for better life and better livelihood of the community. The community justice is the foundation for any public organizations, local communities, and the criminal justice system to control crime and lawlessness in any community. The key target of the community justice depends on the community whether it can be changed from the focus on each case as if the case is occurred, the process shall rely on professional standards and a formal procedure to focus on the 
important of moral principles and traditions as well as public benefits rather than focusing on individual benefits [3].

- 5 components of Community Justice [4].

Community justice focuses on operating in the area and community justice operates at the neighborhood level with the following reasons:

1) Because the final target of the community justice is to develop quality of life and livelihood of the community, so it relies on the accurate information of the boundary of area for evaluation both before and after the implementation whether it can achieve the target or not.

2) Community justice focused on the problem solving before the crime takes place and after the crime took place. Therefore, it is necessary to determine the boundary to study on the information of such area thoroughly, and then bring such information to the problem-solving procedure systematically, especially in the area that the crimes are outbreak. The information is important for the community to make decision together to select issues that need to be resolved before and after according to the accelerate level of the priority areas. Then, goals, strategies, and activities as well as people who shall be drawn into participation shall be determined to join the solution process, and the period to solve problems as well as results obtained from such solution process shall be determined clearly as well.

3) Community justice focuses on the participation of the community in solving community problems through community. The community justice will put effort to do everything to encourage community members to develop a relationship with each other together, so they will feel as they are in the same community, and they will feel that they would like to protect the dignity of their community without allowing anyone to trample the dignity of their community.

Sompong Ittimeechai [5] studied on The participation of the public in Preventing and Suppressing Narcotics Crime in the area of responsibility of the local police station, Na Phra Lan Sub-District, Chalermphrakiet District, Saraburi Province, and it was found that gender, age, education, career, income, trustworthy of people towards police, knowledge on preventing and suppression on drugs have no influence towards the participation in preventing and suppression on drugs with statistically significant. However, the period of habitation in the area is the only factor that influences the participation in participation in preventing and suppression on drugs with statistically significant.

Chusawat Chanrojanakij [6] studied on the participation of the public on crime prevention in the area of responsibility of the Huai Kwang Police Station, and it is found that people in the area of the responsibility of the Huai Kwang Police Station have mid-level participation on crime prevention. The factors affecting the participation of the public on crime prevention as the fundamental individual factors are age, level of education, feature, and experience in criminal case. For example, they are person who have got damages, eyewitnesses, listened from others, including factors of participation such as a focus on crime issues. On the other hand, the faith on polices has no effect on the participation on crime prevention.
Pongthorn Thanyasiri [7] studied on The participation of the public in the administration of the police, and it is found that form of the participation of the public in the administration of the polices of Royal Thai Police is in the form of administrative committee such as policy committee that monitors and evaluates the administration of polices with the mechanism of the participation of the public in the administration of the police. It can be divided in to 4 levels which are national level, provincial level, Bangkok level, and police station level. There are 4 boundaries of the authorization of each level of committee as follows: 1). the authority to define policies to manage existing resources (people, budget, materials, and methods of operation) of police agencies, 2). the authority to determine policy to administrate the prevention of crime and maintaining the internal security of the police agencies, 3 ). the authority to monitor and evaluate the management of existing resources (people, budget, materials, and methods of operation) of the police agencies, and 4). the authority to monitor and evaluate the administration to prevent crime and maintain internal security of the police agencies.

\section{Research Framework}

\begin{tabular}{|c|c|}
\hline & $\begin{array}{l}\text { Concept of community justice } \\
\text { edure that focuses on prevention the criminal prob } \\
\text { community by the community for the communit }\end{array}$ \\
\hline $\begin{array}{l}\text { The pr } \\
\text { and op } \\
\text { implem } \\
\text { evaluat }\end{array}$ & $\begin{array}{l}\text { Concept of the community cooperation } \\
\text { re that stakeholders have expressed and exchang } \\
\text { to seek for alternatives and decisions related } \\
\text { on with all parties from the beginning, m } \\
\text { at lead to the benefits of all parties. }\end{array}$ \\
\hline $\begin{array}{l}- \\
-\end{array}$ & $\begin{array}{l}\text { Persons participating in community justice } \\
\text { Community leader } \\
\text { people } \\
\text { Officers from Ministry of Justice }\end{array}$ \\
\hline & Community Justice Center \\
\hline & $\begin{array}{ll}\text { The cooperation of the community } \\
\text { - } & \text { The awareness of rights and duties } \\
\text { - } & \text { Good attitude towards the participation } \\
\text { - } & \text { Awareness of being representative } \\
\text { - } & \text { The confidence and trust } \\
\text { - } & \text { The exchange of news between members } \\
\text { - } & \text { The consensus conclusion }\end{array}$ \\
\hline
\end{tabular}

\section{Research Methodology}

For the research titled the innovation process management community with case study of Community Justice Center in the province of SuratThani, this time, the research team collected variety of data formats through the study on the basic information from documents and collected data in the community by using the following steps:

1) Secondary data from the document for study and the Internet.

- Study for information from documents containing community basic information, policy goals of the organization, and community justice related law.

- Study for information from structure documents and missions of the organization 
2) The primary data by collecting data from the community that the research team collected from the community.

- For the interview obtained research team in the area, the study on the history of the community, and the change of community from the past to present, the team interviewed seniors and leaders in the community.

- The in-depth interview on the thought belief, tradition, culture and community crime conflict management.

- Observation divided into the observation without participation and participatory observation.

\section{RESUlTS AND DisCUSSION}

The Study on the Context, Political Culture, Social Structure, and Cultural of Local Community under a Multicultural Society which affect the Process Management Community in SuratThani Province.

When indicating about the identity of the rural area in the South, most social perception is the good condition of the economy because local resources are abundant, and most people are hard-core ruffians who are interested in politics. Local people seem to aware of the identity as well as the researcher had found that the various researches related to the context and culture of southern people of many local researchers summarized that southern people are proud and they believe that these identities are the real appearance. After the consideration, it can be seen that both communities are strong because these two communities are from strong religious background. Both communities have close relationship and they help each other until it becomes the area with strong web of social protection, including the community background that people believe the leader of the community. The most important is that southern people are flexible, chatty, disputer, intellectual, and diplomatic people who have never disadvantaged by others. They are outwitted people who never respect other people easily. They love their friends and very sensitive for news and changes. They never afraid of people and they like to face with the truth. The reliance on the government is reduced. The community is strong, and people there believe in their leaders from low to mid-level. However, they still believe in patronage system as the main.

After considering from the cultural context of the southern people, in this point, it facilitated effectiveness on the administration of process management community because most of people from the south manage problems by themselves, and the South has its unique identity.

\section{Management Guideline of the Tha Khoei Community} Justice Center.

- The screening through the community justice board in village level. If it is not successfully done, it enters into the Mediation procedure for the community justice board in sub-district Level.

- Emphasize on proactive approach. The boards mediate within the area of the parties.

- Prevent the use of the patronage system in the mediation procedure by prohibiting people who are relatives to get involved.
- Provide independence to the parties to present evidence, no indication, and provide respect to the decision of the parties. The main function is to make the parties aware of the facts on each situation in order to use for the decision-making of the parties.

- Prevention of political interference and police.

Issues of the foster system or kinship system.

From the study, it is found the people in each community of Tha Rong Chang Sub-District and Tha Khoei Sub-District have close and relevant relationship. Moreover, the community is based on social culture of Southern people that they always take friends into account. If the conflict idea related to the conflict resolving or the mediation of dispute occurs in the community that most people have never entered into the process of the dispute mediation or never received help from the Community Justice Center. Besides, they do not see the work of Community Justice Center that can make sure that the Community Justice Center can resolve problem related to the conflict or unfairness as it can be seen that the community respects the kinship system. And, it can be considered that the Community Justice Center may use power to help their relatives and friends in the same group. After the consideration, the process of management on the Community Justice Center to suppress the disputes are community boards, representatives of community, and people who have duty to compromise. In this case, these people may have relation with any party.

The issues of the redundant role of Community Justice Center with Community Leader and Local Administration Organization.

From the study, it is found that the Community Justice Network in Tha Rong Chang Sub-District and Tha Khoei Sub-District is mostly contained with community leaders, board of the village, including officers from local administration organization, so the Community Justice Center has no understanding in the role of itself because the community leader, at present, has the role to help various government sectors, including officers from local administration organization. For example, in the case of Community Justice Center in Tha Rong Chang Sub-District, the legislature and local administrative organization are assigned to perform the duty. After the consideration, the main role of the legislature is to provide suggestion related to law to publics. With such reason, it can provide the confusion to officers and the publics. Additionally, the publics have seen from the past that if there are any unrested situations occur in the community, the community leader has an obligation to maintain peace. Hence, the publics have seen that the community leader can mediate disputes under the law. Thus, there is an opinion that there is a similarity between the role of Community Justice Center and the role of the community leader. With this reason, the publics does not understand the role of the Community Justice Center.

The issues of the understanding on the actual guideline to establish Community Justice Center.

Sometimes, it is necessary to apply law with work of Community Justice Center. However, it doesn't mean that Community Justice Network must be an expert in law. It presents that the Community Justice Network does not truly understand the process management community. From the 
study, it is found that the process of management on the Community Justice Center focuses on the administration by using law as an indicator and the key guideline to suppress the dispute. On the other hand, it does not take the willingness of both parties into account. It can be considered from the beginning of the consideration, which is the explanation of legal provision. After the consideration, it is seen that guideline and process management community focuses on the suppress of the disputes by depending on the willingness rather than being overcome with legislation aimed to point out under the law. The Community Justice, in this case, focuses on the fairness building under the reality by implementing activities under the management of the community itself, and the activities rely on the identity and culture of each community under the willingness, not to accept under the legal framework.

\section{A. Suggestions}

1) Build an understanding of the actual role of Community Justice Center by using public relations with a proactive approach to the public.

2) Improve stage and implementation guideline to build confidence to the public, particularly on the board that the issues of kinship system shall not be involved.

3) Encourage the community to participate in community justice to encourage the participation of the publics by creating a membership system.

4) Promote independence on the implementation of the Community Justice Center without the dominance of state agencies or the indicative of other local organizations.

5) Lift up the status of the Community Justice Center which has legal support on the correct duty performance, including adequate budget allocation for work implementation.

\section{CONCLUSION}

From the study conducting in this research, it can present the acknowledgment and understanding on the context, political culture, social structure, and cultural of local community which affect the process management community in SuratThani Province to the government and other communities, and it provides innovative management knowledge to apply with the process management community within multicultural society as well as presenting factors affecting successfulness or failure of knowledge on the development of innovative management related to the process management community to this province.

\section{ACKNOWLEDGMENT}

This research was supported by the research and development institute, Suan Sunandha Rajabhat University, Thailand.

\section{REFERENCES}

[1] K. Kittiyarak, A New Paradigm on the Management of Thai Criminal Justice, Bangkok: Duan Tola Publishing, 2007.

[2] W. Suridechakul, "The study of factors affecting the development community using the philosophy of sufficiency economy: A case study of Banbangkrasan community Phra Nakhon Si Ayutthaya Province," J. International Journal of Systems Applications, Engineering \& Development, pp. 14-19, 2016.

[3] C. Tanasugarn, C. Kanchanasuttisang, V. Roma, and M. Samnuanklang, "Community development power network to solve drug problems, community justice network development, department of probation, ministry of justice," Bangkok; Thai Health Promotion Foundation, 2005.

[4] S. Iiemanupong, "The new paradigm of community justice, document of the meeting," Process of the Community Justice, 2003.

[5] S. Itthimeechai, "The participation of the public on the prevention and suppression of narcotics in the responsible area of local police station, Na Phra Lan Sub-District, Chalermprakiet District, Saraburi Province," Master thesis in Development Administration, majoring in Social Development, Faculty of Social Development, National Institute of Development Administration, 2001.

[6] C. Chanrojanakij, "The participation of the public on crime prevention in the area of responsibility of the Hoi Kwang Police Station," Master thesis in Political Science, Graduate School, Ramkhamhaeng University, 2000.

[7] P. Thanyasiri, "The guideline to promote the participation of the publics in the justice system," Bangkok: Ministry of Justice, 2000.

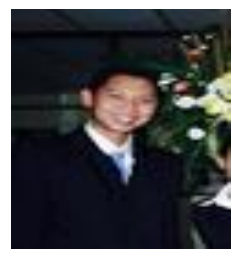

Pattaravis Yoowattana was born on March 19, 1980 He has completed his bachelor in political and master degree in administration and law. He is a lecturer with College of Innovation and Management, Suan Sunandha Rajabhat University, Thailand. His interest is in political. 